\title{
Awareness, Perception and Usage of Nutraceuticals in Indian Society
}

\author{
Anushka Menon ${ }^{* 1}$, Mugdhali Sawant ${ }^{1}$, Shivangi Mishra ${ }^{1}$, Prachi Bhatia ${ }^{1}$, Sejal Rathod ${ }^{2}$ \\ ${ }^{1}$ Department of Biotechnology, Kishinchand Chellaram College, Mumbai, Maharashtra, India \\ ${ }^{2}$ Department of Biotechnology and Microbiology, Kishinchand Chellaram College, Mumbai, Maharashtra, India
}

\section{Article Info}

Volume 8, Issue 5

Page Number : 399-414

\section{Publication Issue}

September-October-2021

\section{Article History}

Accepted : 10 Oct 2021

Published : 19 Oct 2021

\section{ABSTRACT}

During the last few decades, the demand for healthy food and beverages has increased and it is expected to continue increasing in the future. A Nutraceutical is defined as any substance that provides medical or health benefits, including the prevention and treatment of disease. Its constituents are either of known therapeutic activity or contribute substantially to the therapeutic activity of a drug. This research study was dedicated towards a better understanding of nutraceuticals in terms of its awareness, perception and usage by the general public. The study also provided the opinion of clinicians on the same. Sample populations of 650 individuals and 50 clinicians were analyzed in the study. The consumers' willingness towards nutraceuticals was explained through the following predictors- Age group, gender, health perception and occupation. Google forms platform was used to make the questionnaires and was distributed over social media. Data analysis was performed using Google Sheets (Pivot Tables) and Microsoft Excel (Power Query Editor tool). The data was compared and relationships were mapped among the various factors included in the study. The results conclusively depicted that factors like affordability and employment status played a role in the purchase of nutraceuticals. The COVID-19 pandemic played a significant role in influencing consumers to opt for immunity boosting products and supplements. The study was also able to understand the various consumption patterns and opinions of respondents on the different nutraceutical products available in the market. The survey was observed to have increased public awareness in the sample population.

Keywords : Nutraceuticals, Awareness, Dietary supplements, Functional foods, Survey, Therapeutic

\section{INTRODUCTION}

Today, food is not intended to only satisfy hunger and to provide necessary nutrients for humans, but also to prevent nutrition related diseases and improve physical and mental health. In this regard, nutraceuticals play a very important role. The concept 
of nutraceuticals has become popular with respect to health. (Munde, 2016). The importance of food in medicine was recognized by Hippocrates of Cos, who is considered the father of Western medicine. The famous Hippocrates' quote (400 BC), "Let food be thy medicine and medicine be thy food", represents that there has been a great interest in herbal products since decades. There were many historical civilizations, such as ancient Egyptian, Greek, Roman and others that used herbal products and plants in treating and preventing diseases. (Nada A. Helal et al, 2019).

The term nutraceutical is a hybrid or contraction of nutrition and pharmaceutical. Reportedly, it was coined in 1989 by Stephen DeFelice and the Foundation for Innovation in Medicine. DeFelice proceeded to define nutraceutical as, "a food (or part of a food) that provides medical or health benefits, including the prevention and or treatment of a disease" (Poornima Jeyasekaran, 2020). The nutraceutical revolution began in the early 1980s, a continuous stream of published clinical studies followed, defining the potential benefits of a growing range of products on a rapidly expanding array of specific disease processes. (Stephen DeFelice, 1995).

Nutraceuticals may range from isolated nutrients, herbal products, dietary supplements and diets to genetically engineered "designer" foods and processed products such as cereals, soups and beverages. Many of these products hold pertinent physiological functions and valuable biological activities. With the passage of the Dietary Supplement Health and Education Act of 1994, the definition of nutraceuticals has been expanded to include vitamins, minerals, herbs and other botanicals, amino acids and any dietary substance for use by humans to supplement the diet by increasing total dietary intake and subsequently increased the use of nutraceuticals (Patil C.S, 2012). Nutraceuticals are marketed in concentrated forms as pills, capsules, powders and tinctures, either as a single substance or as combination preparations. The recognized health benefits of nutraceuticals are legion. Various products are claimed not only to reduce the risk of cancer and heart disease but also to prevent or treat hypertension, high cholesterol, excessive weight, osteoporosis, diabetes, arthritis, macular degeneration (leading to irreversible blindness), cataracts, menopausal symptoms, insomnia, diminished memory and concentration, digestive upsets and constipation. (Aamir Pasha, 2010). Some nutraceuticals, such as silymarin, curcumin, vitamin E, docosahexaenoic acid, choline and phosphatidylcholine are used in treating and preventing steatosis additionally, many nutraceutical products, such as gallic acid, caffeine, curcumin and others act as anti-aging and antioxidant agents. PUFA1-rich fish oils reduce the risk of coronary cardiovascular diseases and enhance the brain functions. Nutraceuticals are famous for their anticancer efficacy; hence, many nutraceutical ingredients, such as epigallocatechin gallate, curcumin, pomegranate and others, treat different types of cancer, such as breast cancer, prostate cancer and other types of cancer (Nada A. Helal et al, 2019). Nutraceutical products represent a value-added growth opportunity for the agri-food industry, both domestically and internationally. The market is driven by the aging population, rising health care costs, advances in food technology and nutrition, as well as a growing consumer understanding of the link between diet and health. (Prabu et al, 2012).

\section{A. Classification of nutraceuticals}

Nutraceuticals can be classified based on various categories, like on the basis of their natural sources, pharmacological conditions, on the chemical composition of the products, on the basic of market etc. (Debjit Bhowmik et al, 2013)

1) Based on product categories in the market, the nutraceuticals are divided into: 


\section{Functional foods}

Functional Foods are foods that provide health benefits beyond the provision of essential nutrients, when consumed at efficacious levels as part of a regular diet. Some instances of Functional Foods are Omega-3 enriched eggs, Oats, Fatty fish, Fortified margarines, Iodized salts, Soy, Tomato \& tomato products, Probiotic yoghurt, Nuts (Walnuts, Cashews, Pistachios among others), and Leafy Greens. (Assocham, 2017).

Functional beverages

Functional beverages are non-alcoholic beverages containing ingredients that provide specific health benefits beyond those of general hydration. Traditionally, beverages have been fortified with vitamins, minerals, amino acids and antioxidants. Examples of Functional Beverage include performance \& sports drinks, ready-to-drink teas, enhanced water, energy drinks, and soy beverages, enhance fruit drinks. (Assocham, 2017).

Dietary supplements

A dietary supplement is a product intended for ingestion that contains a "dietary ingredient" intended to add further nutritional value to (supplement) the diet, which may otherwise not be consumed in sufficient quantities. Examples of dietary supplements are Vitamins, Minerals, Amino Acids, an herb or other botanical source, a concentrate or an extract. (Assocham, 2017).

2) Based on the different types and their novelty, nutraceuticals are classified into:

Traditional nutraceuticals

Traditional nutraceuticals consist of nutrients, herbals, phytochemicals, Poly unsaturated fatty acids (PUFAs), prebiotics and probiotics, nutraceutical enzymes. (Nada A. Helal et al, 2019).
Non-Traditional nutraceuticals

Non-traditional nutraceuticals consist of fortified nutraceuticals and recombinant nutraceuticals. (Nada A. Helal et al, 2019).

B. Regulation of nutraceuticals in India

Nutraceuticals are considered as foods by the FSS Act, 2006, Rules and Regulations, 2011. The Food Safety and Standards Authority of India (FSSAI) have issued regulations with respect to licensing and registration of food business, manufacturing, packing and labelling, food product standard and so on. In FSSA in India (FSSAI) has defined regulatory guidelines for approval of nutraceuticals in the Indian market. (Swathi Putta, 2020).

\section{Market overview and future trends}

There is rising demand for nutraceuticals worldwide. The annual growth of nutraceuticals was found to be 25\% in India. (Swati Putta, 2020). According to the Global Nutraceutical Market Growth Analysis Report, 2020-2027, the global nutraceutical market size was valued at USD 382.51 billion in 2019 and is expected to expand at a Compound Annual Growth Rate (CAGR) of $8.3 \%$ over the forecast period. Rising healthcare costs, coupled with the growing geriatric population across the world, are anticipated to assist the growth of the global dietary supplements industry over the forecast period. It has been reported that nine out of ten adults consume 55\% minerals and over $50 \%$ vitamins in their daily diets (Grand View Research, 2020). The pharmaceutical companies and FMCG (fast moving consumer goods) suppliers placed a key role in the success of Indian nutraceuticals. Over $64 \%$ of nutraceuticals market in India is occupied with vitamin and mineral supplements (Swathi Putta, 2020). 
The Indian nutraceutical market is dominated by pharmaceuticals and FMCG companies primarily with very few pure-play nutraceuticals companies. Some major companies marketing nutraceuticals in India are Dabur India, GlaxoSmithKline, Consumer Healthcare, Cadila Healthcare, Zandu Pharmaceuticals, EID Parrys, Amway, Himalaya Herbal Healthcare, Baidyanath, Pantanjali, Herbalife, Sami Labs Ranbaxy and Elder Pharmaceuticals (Yasar Arafath, 2020).

Though the health-conscious consumer segment in India is immense, the market has yet not adopted nutraceutical products for regular consumption. Indian consumers are still at the "awareness" or "somewhat interested" stage of the product adoption cycle (Sullivan, 2011). The objective of the study was to understand the extent of awareness and usage of nutraceuticals among the general public with respect to the different age groups and different genders, and to get the professional opinion of clinicians, from various fields of medicine, on nutraceuticals regarding their current and future demand, affordability, safety, future prospects and awareness.

\section{METHODS AND MATERIALS}

The purpose of this study was to determine which characteristics (age, gender, occupation and health) influence the Indian public towards nutraceuticals and related health supplements. With the purpose of obtaining quantitative data for analysis, the survey questionnaire approach was used. Two surveys were designed, one for the general public and another for clinicians.

\section{A. Research study population}

Respondents of all genders and from age 15 to $60 \&$ above, irrespective of gender or caste, were all encouraged to participate in our survey. A total of 650 responses were received for the public survey. The clinician survey received 50 responses. The responses of both surveys were collected over a period of 35 days.

\section{B. Research study area}

The study was conducted on the Indian population from all parts of India. Maximum responses were received from the cities of Mumbai, Pune, Nashik, Chennai and Palakkad.

\section{Procedure}

The primary data for the study was collected using the questionnaires via Google forms, a survey administration software. The public questionnaire was designed, based on the objectives of the study, to gain an insight on the knowledge, opinions and usage of nutraceuticals by the general public. It included three main sections: General information, Participant Opinions and Consumer Behavior. The clinicians' questionnaire was designed based on the objectives of the study, to gain an insight on the knowledge, opinions and recommendations of nutraceutical supplements by clinicians to their patients. It included two main sections: General information and Participant Opinions. The questionnaire included three-way questions, open-ended questions, multiple choice and checklist questions.

\section{Data analysis}

The analyses of the data collected was performed using Microsoft Excel and Google Sheets. For the public survey, Excel functions like COUNTIF were used to count cells in a range that meet a single condition for the first two sections of the questionnaire. Using this function, it was simple to obtain information such as the number of respondents by each specific gender, age, occupation, city and health condition. The relationships between the various factors and attributes in our study were analyzed and patterns were established using Pivot Tables. Each of the attributes (age, gender, occupation and health) were analyzed against the objectives of 
the survey. For analysis of the checkbox questions, an excel tool called Power Query Editor was used to transform the data and then the results were analyzed with Pivot Tables and Charts. These data transformations included the following steps: split the columns, sort \& filter columns and unpivot data to use for pivot tables. All analyses of the clinician survey were carried out using Microsoft Excel (COUNTIF).

\section{RESULTS AND DISCUSSION}

\section{A. Results}

1] Public survey

The public survey was circulated over social media among friends, family, colleagues and their acquaintances, spanned across the various states of India. 650 responses were received at the end of the survey collection. $58.6 \%$ of the respondents were female, while $41.4 \%$ were male. It was observed that $26.46 \%$ of women (172) and $20.62 \%$ of the male respondents reported that they had heard of the term "Nutraceutical". The respondents were of the following four age groups - Young adults between the age group of 15-25, Adults between 26-40 years, Middle-aged adults between 41-60 years and aged, above 60 years. The majority of respondents who were familiar with the term "Nutraceuticals" were young adults, around $18.15 \%$ (118). They were followed by middle-aged adults at $16.92 \%$ (110), adults at $9.54 \%$ (62) and aged people at $2.46 \%$ (16) (Graph 1).

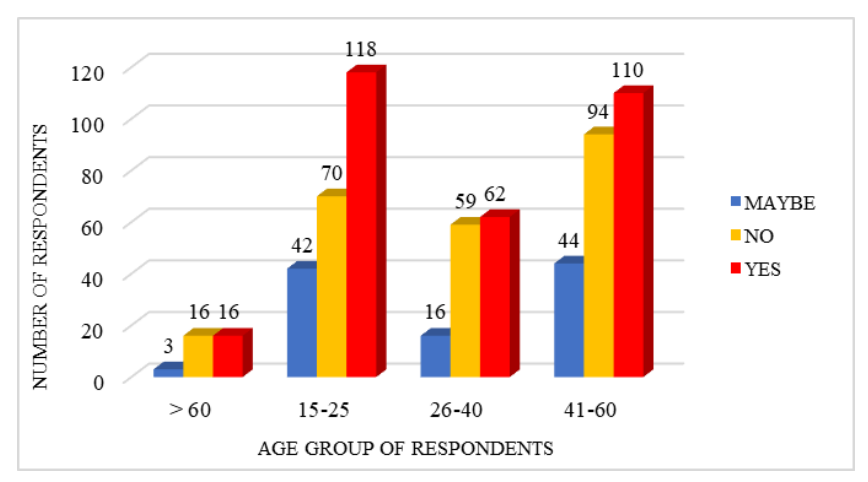

\section{Graph 1: Awareness of the term "Nutraceuticals" among the various age groups of respondents.}

Out of 650 respondents, 306 people (i.e., 47.1\% ) reported that they recognized the term "Nutraceutical", while 239 people (i.e., 36.8\%) had never heard the term nutraceutical. When the respondents were asked about having seen a commercial of any nutraceutical products like Chyawanprash, sports drinks or vitamins, 604 people replied that they had.

Out of the 650 respondents about 409 respondents have consumed a nutraceutical at some point in their life. The most common nutraceuticals used among the respondents who did consume nutraceuticals were observed to be Chyawanprash, Vitamin C supplements by Amway, Nutrilite and probiotics like Yakult. (Graph 2)

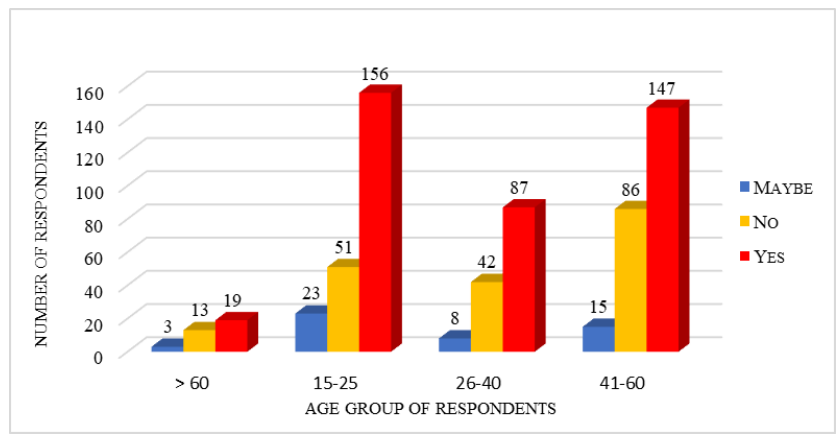

Graph 2: Consumption of nutraceutical according to respondents' age group.

Nutraceuticals are generally recognized as safe at prescribed dietary doses. Most of the respondents (about 372 people) across all age groups showed uncertainty when asked about the safety of nutraceuticals. However, 32\% of respondents regard them as safe.

Out of 650 respondents, only 20 reported to have reacted negatively to a health supplement. Most of the reactions were issues related to hair-fall and gastric problems like constipation. Nausea and fever were also reported. 
It was also noted that 156 respondents were found to consume nutraceuticals regularly. These nutraceuticals include supplements such as Vitamin C, Vitamin D, Vitamin B12 and B complex along with multivitamins, zinc supplements, whey protein (Proteinex), becosules, and calcium tablets.

When respondents were asked about their belief in preventive therapy over curative therapy, 504 respondents reported that they believed in the prevention of a disease/deficiency over being treated after the disease/deficiency had already developed (Graph 3).

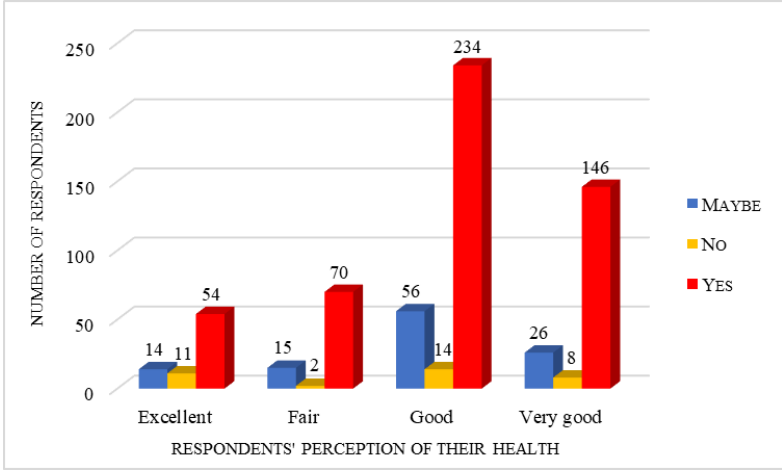

Graph 3: Respondents' belief in preventive therapy over curative therapy according to their health.

The roots of the concept of nutraceuticals and functional foods can be traced to the ancient Ayurvedic system of health care. 209 respondents of age group 26-60 and 104 respondents of age group 1525 were more inclined to use nutraceutical supplements if it was associated with Ayurveda over modern medicine. (Graph 4)

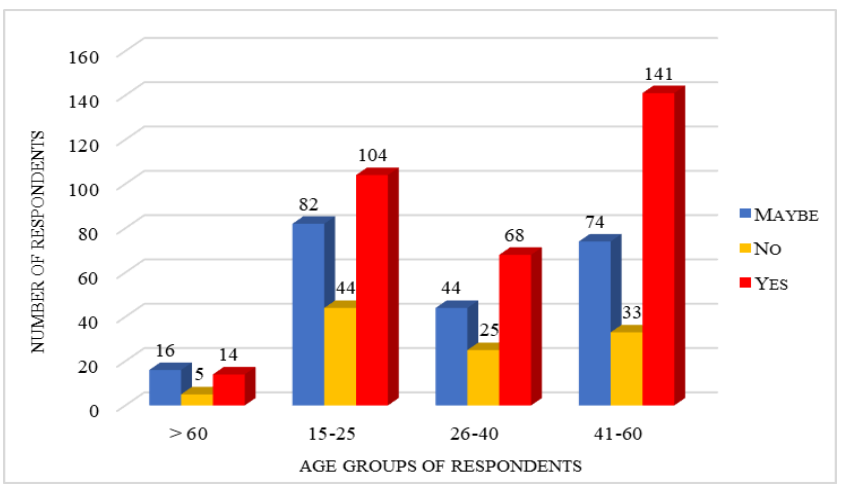

Graph 4: Respondents' willingness to use Ayurvedabased nutraceuticals over modern medicine according to their age groups.

The COVID-19 pandemic has placed an emphasis on building immunity, in order to efficiently fight the coronavirus. As a result of this, nutraceuticals have been gaining more importance. Our study evidenced this as 233 female respondents and 148 male respondents were seen to prefer nutraceutical supplements to boost their immunity instead of commercial drugs. Out of 650 respondents, 50 respondents tested covid-19 positive during the pandemic and they reported that they were prescribed nutraceutical supplements for treatment. The most common ones were Vitamin C, Vitamin D, B complex and Multivitamins tablets.

Nutraceutical supplements are usually sold over-thecounter by chemists. However, 300 respondents reported that they would be more inclined to consume nutraceutical supplements if they were prescribed by a registered medical practitioner.

The standards for Health supplements and Nutraceuticals are specified under the FSSAI (The Food Safety and Standards Authority of India). Out of 650 respondents, 415 respondents were aware about FSSAI being the regulatory body governing nutraceuticals among respondents.

According to the 650 respondents, the affordability of nutraceuticals was observed to be an important factor in choosing to consume nutraceutical supplements. 217 respondents would not consider out-of-pocket spend on nutraceuticals.

An enormous amount, 536 respondents, also believed in the importance of having a basic understanding and knowledge about herbal and dietary supplements before using them. 
In the survey section titled, "Participant Opinions", the participants were asked whether they agreed or disagreed (on a five-point scale from "strongly agree" to "strongly disagree") with each of thirteen general statements about the role of nutraceuticals or dietary supplements in the context of a healthy diet and lifestyle. The subjects' agreement or disagreement with the thirteen health belief statements are presented in Table 1.

TABLE 1: PERCENTAGE DISTRIBUTION OF RESPONDENTS BY AGREEMENT OR DISAGREEMENT WITH HEALTH BELIEF STATEMENTS

\begin{tabular}{|c|c|c|c|}
\hline \multirow[b]{2}{*}{ STATEMENT } & \multicolumn{3}{|c|}{$\begin{array}{l}\text { RESPONSE OF } 650 \text { INDIVIDUALS } \\
\text { (In percentage) }\end{array}$} \\
\hline & $\begin{array}{l}\text { Strongly agree/ } \\
\text { Agree }\end{array}$ & Neutral & $\begin{array}{l}\text { Strongly disagree/ } \\
\text { Disagree }\end{array}$ \\
\hline $\begin{array}{l}\text { 1.Dietary supplements are needed if a person } \\
\text { feels tired and rundown. }\end{array}$ & 68.3 & 25.7 & 6 \\
\hline $\begin{array}{l}\text { 2.Dietary supplements help in increasing } \\
\text { one's physical health }\end{array}$ & 73.4 & 22.5 & 4.1 \\
\hline $\begin{array}{l}\text { 3.Most people consume a well-balanced diet } \\
\text { everyday containing all the nutritional } \\
\text { elements. }\end{array}$ & 30.3 & 27.5 & 42.1 \\
\hline $\begin{array}{l}\text { 4.Dietary supplements usually help in } \\
\text { improving a person's appearance. }\end{array}$ & 47.3 & 36.8 & 16 \\
\hline $\begin{array}{l}\text { 5.Body fat can be lost by taking certain type } \\
\text { of dietary supplement combined with } \\
\text { exercise. }\end{array}$ & 39 & 33.2 & 27.7 \\
\hline $\begin{array}{l}\text { 6.One can skip meals and just take dietary } \\
\text { supplements. }\end{array}$ & 7.5 & 12.3 & 80.1 \\
\hline $\begin{array}{l}\text { 7.The nutrients supplied by food need to be } \\
\text { supplemented with nutraceuticals. }\end{array}$ & 34 & 39.7 & 26.4 \\
\hline $\begin{array}{l}\text { 8. Nutraceuticals hold great potential for the } \\
\text { future because they are convenient for } \\
\text { today's lifestyle. }\end{array}$ & 59.1 & 30 & 10.9 \\
\hline $\begin{array}{l}\text { 9. Nutraceutical supplementation could play } \\
\text { a role in treating malnutrition in the } \\
\text { impoverished populations of India. }\end{array}$ & 62.3 & 26.6 & 11.1 \\
\hline $\begin{array}{l}\text { 10. Diet should be rated more highly by } \\
\text { consumers than exercise or hereditary } \\
\text { factors for achieving good health. }\end{array}$ & 55 & 29.1 & 15.8 \\
\hline $\begin{array}{l}\text { 11. By using nutraceuticals, it may be } \\
\text { possible to reduce or eliminate the need for } \\
\text { conventional medications, reducing the } \\
\text { chances of any adverse effect. }\end{array}$ & 50.8 & 39.4 & 9.8 \\
\hline $\begin{array}{l}\text { 12. Healthy individuals can/should take } \\
\text { nutraceuticals to maintain health. }\end{array}$ & 41.8 & 37.8 & 20.3 \\
\hline $\begin{array}{l}\text { 13. There is a lack of awareness about } \\
\text { nutraceutical supplements and the range of } \\
\text { supplements available in the market. }\end{array}$ & 82.3 & 15.2 & 2.5 \\
\hline
\end{tabular}


A majority of respondents, i.e., 53.4\% agreed that dietary supplements are essential if a person feels tired and $8.62 \%$ of these were regular users. Multivitamins and supplements have demonstrated evidence in improving skin appearance. $39.08 \%$ of the respondents endorsed the fact that dietary supplements usually help in improving a person's physical appearance whereas $36.77 \%$ had a neutral point of view.

Majority of the respondents, approximately 39.69\%, held a neutral opinion on whether nutraceuticals should be supplemented with everyday food, while $34 \%$ respondents agreed and $26.3 \%$ disagreed. Significant neutral opinions were also observed in the statements, "Body fat can be lost by taking certain type of dietary supplement combined with exercise." and "Healthy individuals can/should take nutraceuticals to maintain health."

Nutraceuticals are potential elements to improve productivity, quality of life. They also hold great potential for the future because they are convenient for today's busy lifestyle. A majority of the respondents, approx. $59.08 \%$ agreed with this statement. Preventing and treating malnutrition with nutraceutical supplementation could also play a role in treating malnutrition in the impoverished populations of India. $62.3 \%$ of the respondents agreed with this statement. It was also observed that half the total number of respondents i.e., $50.77 \%$, agreed that by using nutraceuticals, it may be possible to reduce or eliminate the need for conventional medications, reducing the chances of any adverse effect. A considerable majority of respondents, $82.3 \%$, also opined that there is lack of standardization and awareness about nutraceutical supplements.

In order to understand the extent of usage of nutraceuticals, the final factor analyzed was Consumer behavior. From the list of nutraceuticals provided to them, the majority of respondents reported to have used Multivitamin tablets (408 out of 650) followed by Green tea (381), Vitamin C (372), Calcium tablets (356), Vitamin D (351) (Graph 5).

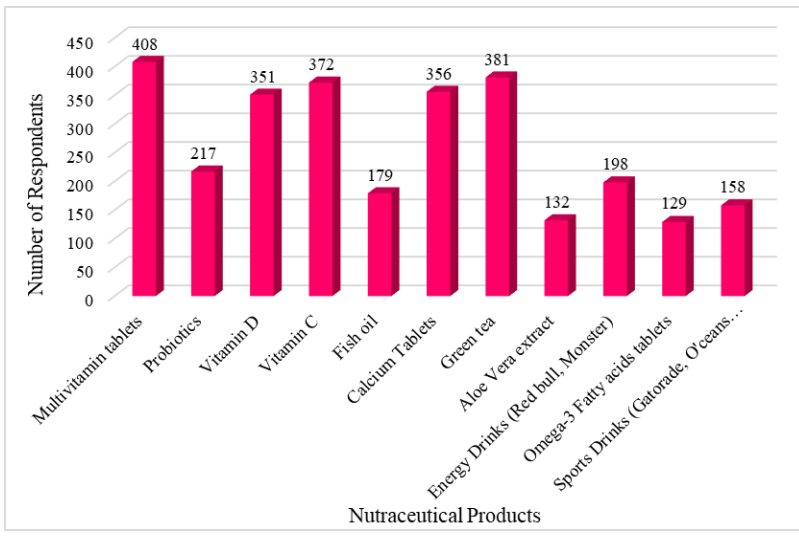

Graph 5 : The most commonly used nutraceuticals and their usage in each category.

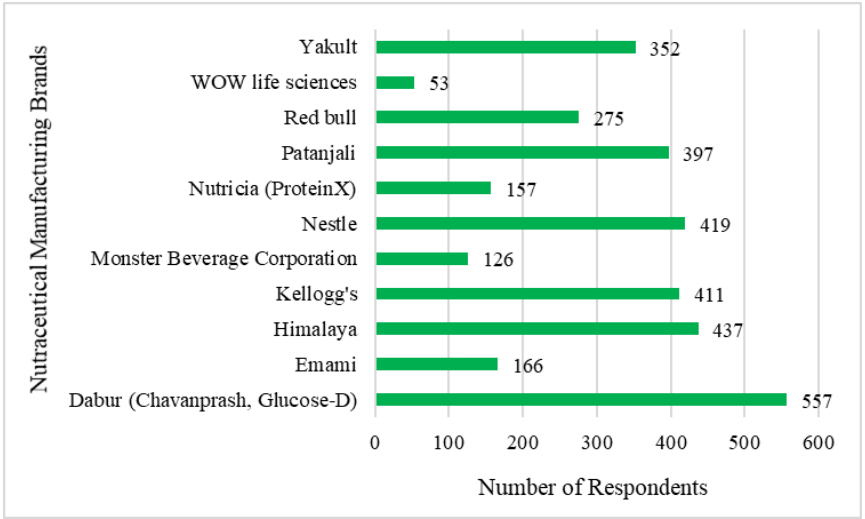

Graph 6 : The most commonly known nutraceutical manufacturing brands and their consumer recognition.

The general consensus for choosing a health supplement was found to be based on the desired results of the supplement and absence of side effects (487 and 461 respectively).

As for the physical form of the supplement, majority of the respondents reported that they consumed nutraceuticals in the Tablet form (452) followed by Capsules (336), liquid (225) and powders (157) in the reducing order.

When asked about the reason for consuming nutraceuticals, around 431 respondents did so, based on advice from a healthcare professional/clinician. 294 respondents consumed it for its perceived health benefits.

According to the respondents, the benefits offered by nutraceuticals were observed to be that they provided additional supplementation of nutrients which are lacking in daily diet (511), while also playing a role in avoiding certain health conditions (317) (Figure 1). 


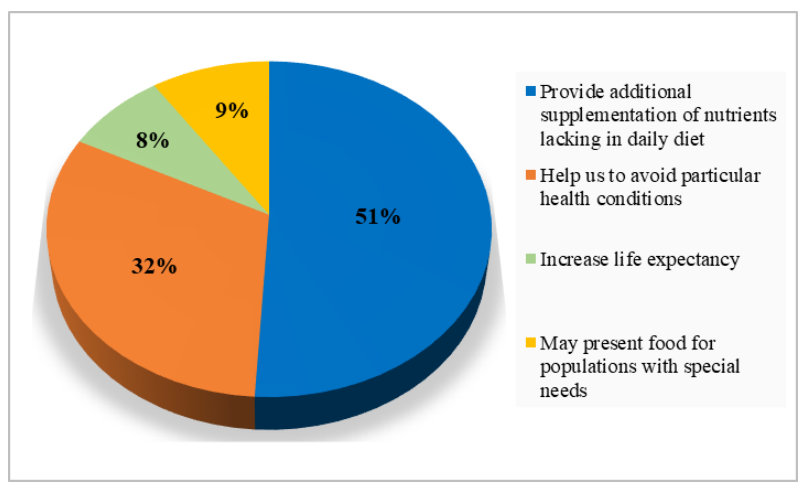

Figure 1 : The potential benefits of nutraceuticals as viewed by the respondents.

A majority of the respondents, around 403 of them, reported that they used supplements based on recommendations/information obtained from official journals and professionals. Others based their choices on product labels (271), educational programs (192), consulting health food stores (179) and textbooks (60).

One of the highlights of this study was to find out what are and could be the obstacles in the awareness of nutraceuticals.

A big portion of respondents, around 452 of them, thought that it was lack of information regarding the efficacy of the nutraceuticals and 425 of them thought it was the level of consumer's knowledge about them.

Another factor was the affordability of nutraceuticals (225), as many people were not sure if they were willing to pay a high price for nutraceutical supplements. Access and availability also emerged as a factor as opined by 152 respondents (Figure 2).

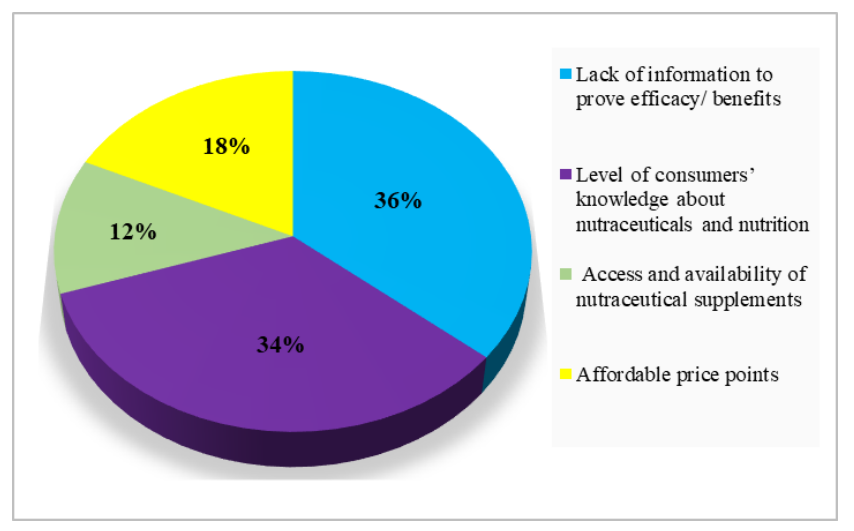

Figure $2:$ The obstacles in the awareness and consumption of nutraceuticals as viewed by the respondents.

\section{2] Clinician Survey}

The survey was circulated among clinicians across all major specialties which includes general practitioners, physicians, nutritionists, gynecologists, dentists, cosmetologists and pharmacists. A total of 50 responses were received.

36 out of 50 clinicians agreed that there is a need for nutraceuticals in current time. Cost and availability play an important role in awareness and usage of nutraceuticals among different economic groups. Only 12 clinicians agreed that the use of nutraceuticals is economical for patients.

It was also observed that out of all the 50 respondents, 26 clinicians generally recommend nutraceutical supplements to people belonging to the 41- 60 age group, while 20 clinicians recommend nutraceuticals generally to patients belonging to the 26-40 age group.

30 clinicians generally prescribed nutraceutical supplements before a problem or deficiency develops into a disease, while 13 clinicians prescribe it after the disease has developed. 7 clinicians were observed to prescribe nutraceutical supplements only when traditional treatment has failed or not shown any progress.

When asked about the physical form of the supplement usually prescribed, 22 clinicians recommend it in the tablet form, while 16 clinicians recommend it in powder form. A majority of the clinicians i.e., 32 of them, generally recommend multivitamins to their patients, 6 of them recommend probiotics, while 5 of them recommend calcium tablets. Other supplements being recommended were observed to be protein supplements, and Coenzyme Q10.

The intake of dietary supplement is generally safe, but not totally without risk. According to the data analysis, 34 clinicians confirmed that no side effects or adverse drug reactions were experienced by their patients due to the consumption of nutraceutical supplements

According to our survey analysis, a majority of clinicians i.e., 38 of them, predicted a major increase in the demand for health supplements in future as compared to the current statistics. On the other hand, 12 clinicians believed that the demand for health supplements will remain stable/ constant (Figure 3). 


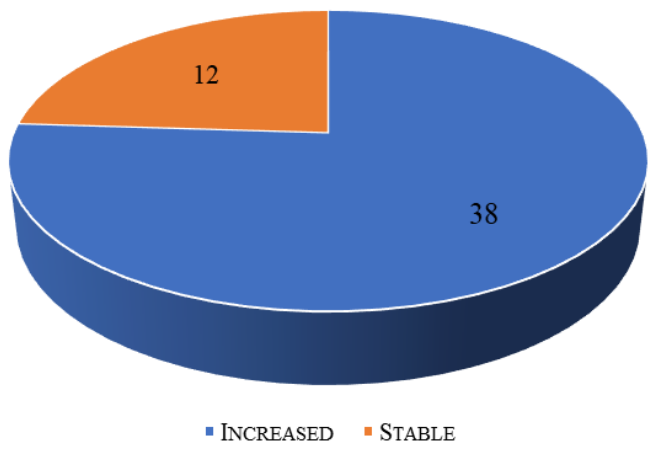

Figure 3 : Prediction of demand for health supplements in the future

The biggest obstacle in the awareness and consumption of nutraceutical supplements reported by 22 clinicians is the lack of information to prove its benefits. 15 clinicians also opined that it was the low level of consumer's knowledge about nutraceuticals that contributed to a decrease in the consumption rate and 12 clinicians believed that the unavailability of the supplements at an affordable price was also an important factor.

In a section titled, "Participant Opinions", the clinicians were asked whether they agreed or disagreed (on a fivepoint scale from "strongly agree" to "strongly disagree") with each of ten general statements about the current and potential uses of nutraceutical supplements in the health industry, their safety, and the different perceptions amongst clinicians regarding them (Table 2).

TABLE 2 : PERCENTAGE DISTRIBUTION OF CLINICIANS BY AGREEMENT OR DISAGREEMENT WITH THE PROVIDED STATEMENTS

\begin{tabular}{|c|c|c|c|}
\hline \multirow[b]{2}{*}{ STATEMENT } & \multicolumn{3}{|c|}{$\begin{array}{l}\text { RESPONSE OF 50 CLINICIANS } \\
\text { (In percentage) }\end{array}$} \\
\hline & $\begin{array}{l}\text { Strongly agree/ } \\
\text { Agree }\end{array}$ & Neutral & $\begin{array}{c}\text { Strongly disagree/ } \\
\text { Disagree }\end{array}$ \\
\hline $\begin{array}{l}\text { 1. I know how nutraceuticals work and how to } \\
\text { recommend them to my patients. }\end{array}$ & 82 & 14 & 4 \\
\hline $\begin{array}{l}\text { 2.I regularly include nutraceuticals in my } \\
\text { recommendations for patients. }\end{array}$ & 58 & 24 & 18 \\
\hline $\begin{array}{l}\text { 3. I would recommend that my family } \\
\text { members/friends use nutraceutical supplements if } \\
\text { they are unwell and also include them in daily diet } \\
\text { for overall well-being. }\end{array}$ & 70 & 24 & 6 \\
\hline $\begin{array}{l}\text { 4. I think that nutraceutical supplements could } \\
\text { help in combating malnutrition in impoverished } \\
\text { populations. }\end{array}$ & 82 & 16 & 2 \\
\hline $\begin{array}{l}\text { 5. Nutraceutical supplements can be used to } \\
\text { increase health in times of physical weakness. }\end{array}$ & 84 & 14 & 2 \\
\hline $\begin{array}{l}\text { 6. Nutraceuticals should be sold only on } \\
\text { prescription of a registered medical practitioner. }\end{array}$ & 60 & 26 & 14 \\
\hline $\begin{array}{l}\text { 7. Nutraceuticals are relatively safer to use than } \\
\text { chemically designed pharmaceuticals. }\end{array}$ & 62 & 30 & 8 \\
\hline $\begin{array}{l}\text { 8. Pharmaceuticals are safer than nutraceuticals as } \\
\text { they undergo documented clinical trials before } \\
\text { being released and approved for use. }\end{array}$ & 42 & 38 & 20 \\
\hline $\begin{array}{l}\text { 9. More information regarding nutraceutical uses } \\
\text { like dosage, formulation, adverse effects, drug } \\
\text { interaction is necessary. }\end{array}$ & 94 & 6 & 0 \\
\hline $\begin{array}{l}\text { 10. Pharmaceutical drugs must be used when } \\
\text { necessary to treat serious diseases and prevent } \\
\text { death while nutraceuticals must be used to } \\
\text { enhance general health. }\end{array}$ & 80 & 14 & 6 \\
\hline
\end{tabular}


A majority of the clinicians, i.e., 41 of them, opined that they knew how nutraceutical supplements worked and how to recommend them. 29 clinicians regularly included nutraceutical supplements in their recommendations. 41 clinicians agreed that nutraceutical supplements could be potentially useful in combating malnutrition among impoverished populations or populations with certain special needs. 42 clinicians also agreed that it was ideal to use nutraceutical supplements in times of physical weakness for quick results and recovery.

Based on our results from the general public survey, around 300 respondents (out of 650) believed that they would be more inclined to trust nutraceutical supplements if they were prescribed by a registered medical practitioner. Clinicians, on the other hand had a divided opinion on this. 30 of them agreed while 7 disagreed with the statement.

Regarding the overall safety of nutraceuticals, most clinicians opined that nutraceutical products, being natural compounds, are relatively safe to consume but it is necessary for them undergo documented clinical trials like pharmaceuticals, before being deemed safe for human consumption.

A broad generalization regarding nutraceuticals is that they are wellness products and should be used to enhance general health, while conventional pharmaceutical drugs must be used for treatment of diseases. While 40 clinicians endorsed this statement, 3 clinicians disagreed. 7 clinicians chose a neutral stance on this.

As for the current market knowledge regarding the uses, chemical properties like formulation, drug interactions, adverse effects and optimum dosages, 47 clinicians agreed that it was imperative to have updated research and more information about nutraceutical supplements.

\section{B. Discussion}

Nutraceuticals have the advantage over medicines since they avoid side effects and are naturally dietary supplements. This study sought to check the awareness of nutraceuticals among the general public and get the perspectives of both, the general public and clinicians, on nutraceuticals and their use and consumption.

There is great inconsistency in terms of reach and penetration of nutraceuticals in urban and rural Indian markets, which is mainly concerned with consumer awareness and perception. There is still something lacking in terms of product penetration, knowledge and usage, especially among the economically backward areas. This is why there is a need perform more studies and research in this topic. The lack of prescriptions contributes to the sale of these products without actual studies on its claimed results. Therefore, there is a need to bring out all the aspects of nutraceuticals in society through awareness, so that more accurate research could be contributed to the topic.

An important factor analyzed in our survey, "Awareness, Perception and Usage of Nutraceuticals in Indian society" was the awareness of nutraceuticals among all the age groups of the public. According to the results, $47.1 \%$ of the respondents reported that they had heard the term "Nutraceutical" at some point in their life, while $36.8 \%$ had never heard it. The majority of respondents who were familiar with the term "Nutraceuticals" were young adults, around 18.15\% followed by middle-aged adults at $16.92 \%$ adults at $9.54 \%$ and aged people at $2.46 \%$.

A similar study (with a sample size of 502 respondents) was conducted by Arsenia J. Cruz et al (2000), where it was found that in their study, 37.5\% of respondents were aware of nutraceutical products and $62.5 \%$ were not aware of them. The majority of respondents who were not aware of nutraceuticals were elderly (40.1\%) and women $(54.1 \%)$.

Respondents were also asked about their beliefs in preventive therapy over curative therapy. Out of 650 respondents, 504 respondents believed in the prevention of a disease/deficiency over being treated after the disease/deficiency had already developed. T. U. Zaman et al (2017), in their study titled, "Nutraceuticals: a slow transition from preventive to curative healthcare", found that there is a slow transition from the curative form of treatment to the preventive form of treatment. 
According to the results of our study, the majority of respondents reported to have used Multivitamin tablets (62.8\%), followed by Green tea (58.6\%), Vitamin C (57.2\%), Calcium tablets (54.8\%) and Vitamin D (54\%). In the survey study conducted by Atta Abbas Naqvi (2018), on dietary supplement use among college students, it was reported that, the prevalence of multivitamins and whey proteins was approximately $23 \%$.

In the present study, the respondents were asked about the factors they consider while choosing to consume a nutraceutical. According to the 650 respondents, the price of nutraceuticals was observed to be an important factor in choosing to consume nutraceutical supplements. However out of 650 respondents 217 respondents would not consider out-of-pocket spend on nutraceuticals. Meagan N Vella et al (2014) in his study on functional food awareness in older adults reported that price ranked fifth as a factor that would promote consumption (48.0\%).

A majority of the respondents in the survey, around $62 \%$ of them, reported that they used supplements based on recommendations obtained from official journals and professionals. Others based their choices on product labels (41.7\%), educational programs (29.5\%), consulting health food stores $(27.5 \%)$ and textbooks (9.2\%). It was also reported by Meagan N Vella et al (2014), that related to awareness and knowledge, over half of participants (56.5\%) actively seek out information about functional foods with the most common sources of information being food labels (74.3\%), newspapers, magazines and/or books $(71.7 \%)$ and family and/or friends (54.9\%).

The current survey questioned the respondents if they would be more inclined to consume nutraceutical supplements if they were prescribed by a registered medical practitioner, 300 respondents reported that they would indeed be more inclined, while 243 respondents were somewhat uncertain. Similarly, in the study carried out by Navyashree et al (2016), the percentage of respondents who said that nutraceuticals should be sold only on prescription of registered medical practitioners was $78 \%$.
According to the respondents, the benefits offered by nutraceuticals were observed to be that they provided additional supplementation of nutrients which are lacking in daily diet $(78.6 \%)$, while also playing a role in avoiding certain health conditions $(48.8 \%)$. Around $14.5 \%$ respondents also believed that they increased life expectancy and $12.5 \%$ thought that they could present food for populations with special needs. David R. Axon et al (2017) reported the most common reasons students used dietary or herbal supplements was to prevent disease (24\%), improve physical performance (19\%) and improve immune function (16\%). Tsuyoshi Chiba (May 2020), in his study, reported that most of the students were using dietary supplements to supplement their nutrient intake (70.6\% in all) and to maintain their health $(42.4 \%)$.

A survey for Clinicians was designed, aimed at understanding the clinicians' opinions and the extent of recommendations of nutraceutical supplements to their patients. According to the results of the survey, $58 \%$ of the clinicians regularly included nutraceutical supplements in their recommendations. It was observed that nutraceutical supplements were generally recommended to people belonging to the 41- 60 age group and the 26-40 age group. In a study conducted by Navyashree et al (2016), with a sample size of 50 as well, 54\% prescribed nutraceuticals in their daily practice. They generally preferred to prescribe in the elderly age group, i.e., $24 \%$ preferred nutraceuticals in the age group of 46 to 64 years and $9 \%$ for age groups above 65 years.

$3.1 \%$ (20 respondents out of 650 ) reported to have experienced negative effects, such as gastritis, nausea and hair fall, on using a health supplement. The study conducted by Chiharu Nishijima et al (2019) also reported that the prevalence of adverse events amounted to $9.4 \%$ in males and $14.4 \%$ in females. Gastrointestinal symptoms such as "diarrhea" and "nausea and vomiting" were experienced the most.

According to the current survey analysis, most commonly prescribed supplements by the clinicians were Multivitamins, Probiotics and Calcium Tablets. T. U. Zaman et al (2017), in their study titled "Nutraceuticals: a slow transition from preventive to 
curative healthcare", found that vitamins comprised the largest chunk of supplements prescribed.

Increased demand of nutraceuticals products in India evidenced their possible success rate in prevention and treatment of diseases. Hence, it needs regulatory authorities on product quality and safety in order to minimize the adverse events, toxicity, adulteration, misuse, overdose during human consumption. As food products are reaching from one country to another, maintaining safety and quality standards as per various regulatory guidelines set by the respective governments becomes important. To maintain quality and safety concerns of nutraceuticals all the new companies and existing companies should follow the regulatory guidance of FSSAI for better use.

\section{CONCLUSION}

This study was designed to observe, build and increase awareness of nutraceuticals among the Indian general public through a questionnaire. The usage pattern and current market of nutraceuticals were also discussed. During the analyses, four major variables including age group, health, occupation and gender were considered. The professional opinion of clinicians on the extent of awareness and usage of nutraceuticals was also studied.

A total of 650 responses from the general public and 50 responses from clinicians were collected. At the end of the survey, awareness among the general public was observed to have increased by $22.6 \%$. In conclusion, the survey study proved that nutraceuticals play an important role in an individual's health and lifestyle. These results provided a vital understanding about the awareness and usage of nutraceuticals and health supplements.

The nutraceutical industry is growing at a rate far exceeding the expansion in the food and pharmaceutical industries (Assocham, 2019). Being natural and having less or no side effects, nutraceuticals may be used in prevention of diseases and may hold great potential for future lifestyle. The increased awareness and consumption of nutraceuticals has increased the demand for more information and clinical trials. Lack of standardization was seen as most important obstacle in widespread awareness and consumption of nutraceuticals so long-term clinical studies and supporting evidence is required to authorize nutraceuticals in disease treatment. Their success will be governed by the control of purity, safety and efficacy without inhibiting innovation.

For future approach, comparative studies can be performed to confirm whether the desired isolated substance has the same efficacy, when ingested in a concentration form, as when naturally present in a whole food and the effect of the COVID-19 pandemic on the nutraceutical market/industry and its impact on the mindset of people can be studied.

\section{ACKNOWLEDGMENTS}

The authors would like to extend their deepest gratitude to the DBT star status grant and Kishinchand Chellaram College for giving them the opportunity to conduct their research project and giving them access to all the facilities that they required. The authors also express their heartfelt appreciation for all the survey participants, who took the time out of their busy schedules during the pandemic, to put forward their perceptions about nutraceuticals.

\section{REFERENCES}

[1]. Poorna, A., Sathyabama, M., Venkatesh, M. P., Jeyasekaran, P., Lakshmi, R. S., Prabhavathi, S., Raja, S. S. (2020). Awareness on Functional Foods and Nutraceuticals for Educated Working Women, IJCRT, Volume 8, Issue 6. https://doi.org/10.4103/2278-019x.146160

[2]. Pasha, A. (2010). current trends and opportunities for nutraceuticals in Indian market, Rajiv Gandhi University of Health Sciences, pp-01- 167.

[3]. Alkhatib, A., Tsang, C., Tiss, A., Bahorun, T., Arefanian, H., Barake , R., Khadir,A., Tuomilehto,J. (2017) Functional Foods and Lifestyle Approaches for Diabetes Prevention and Management ， Nutrients, 9, 1310. https://doi.org/10.3390/nu9121310

[4]. Gosslau, A., Chen, K. Y. (2004). Nutraceuticals, Apoptosis, and Disease Prevention, Nutrition Volume $\quad 20 \quad$ Number 1. https://doi.org/10.1016/j.nut.2003.09.017 
[5]. Charles, A., Wadhwa, M. (2011). Global Nutraceutical Industry: Investing in Healthy Living, Frost \& Sullivan, FICCI .

[6]. Santini, A., Novellino, E. (2017). To Nutraceuticals and Back: Rethinking a Concept, Foods, 6, 74; https://doi.org/10.3390/foods6090074

[7]. Stellavato, A., Pirozzi, A. V. A., Giori, A. M., Schiraldi, C., Novellis, F., Scognamiglio,I., Rosa,M., Vassallo, V. (2018) In vitro assessment of nutraceutical compounds and novel nutraceutical formulations in a liver-steatosis-based model, Lipids in Health and Disease, https://doi.org/10.1186/s12944-018-0663-2

[8]. Cruz,A J., Tanchoco, C.C. (2000). Survey on Awareness, Perception, and Extent of Usage of Nutraceuticals and Dietary Supplements in Metro Manila , JOURNAL OF MEDICINAL FOOD Volume $\quad 3, \quad$ Number 4. https://doi.org/10.1089/jmf.2000.3.181

[9]. Ravindran, A., Rai, M., Navyashree R, (2017). Awareness And Practices Towards Nutraceuticals Among Medical Practitioners of A Tertiary Care Teaching Hospital in South India - A Pilot Study , IOSR Journal of Dental and Medical Sciences (IOSR-JDMS) ,Volume 16, Issue 5 Ver. VI , PP 1216. https://doi.org/10.9790/0853-1605061216

[10]. Naqvi, A. A., Ahmad, R., Elewi, A. A. W., AlAwa, A. H., Alasiri, M. J. (2018). Dietary supplement use among undergraduate male students in health and non-health cluster colleges of a public sector university in Dammam, Saudi Arabia , BMC Complementary and Alternative Medicine , 18:269. https://doi.org/10.1186/s12906-018-2332-4

[11]. Hussain, B., Sajid, M.A., Nabeel, M., Saeed, A., Shah, A.A. (2020). Study of assessment of knowledge of patients and health care professionals about the use of nutraceuticals, World Journal of Pharmaceutical Research, Volume 9, Issue 6, 49-119.

[12]. Kar, B., Prafulla K., Ray, B. R., Mishra, S. S. (2018). Advances in Probiotics, Prebiotics and Nutraceuticals, Innovations in Technologies for Fermented Food and Beverage Industries, Food
Microbiology and Food Safety,chapter 7. https://doi.org/10.1007/978-3-319-74820-7_7

[13]. Braun M., Venter I. (2008). Use of dietary supplements, and awareness and knowledge of the recommended fruit and vegetable intakes and consumption of health food store customers in the Cape Town city bowl , S Afr J ClinicalNutra;21(4):323-330. https://doi.org/10.1080/16070658.2008.11734174

[14]. Gallardo, C. C., Far, G. A., Fuentes, P., Crespo, F., Maccionia, R. B. (2012). Can Nutraceuticals Prevent Alzheimer's Disease? Potential Therapeutic Role of a Formulation Containing Shilajit and Complex B Vitamins, Archives of medical research 43 ,699-704. https://doi.org/10.1016/j.arcmed.2012.10.010

[15]. Nishijima, C., Kobayashi, E., Sato, Y., Chiba, T. (2019). A Nationwide Survey of the Attitudes toward the Use of Dietary Supplements among Japanese High-School

Students,Nutrients2019,11,1469. https://doi.org/10.3390/nu11071469

[16]. Edel, C., Axon, D. R., Vanova, J., Slack, M. (2016). Dietary Supplement Use, Knowledge, and Perceptions Among Student Pharmacists,American Journal of PharmaceuticalEducation,81(5)Article92. https://doi.org/10.5688/ajpe81592

[17]. McClements, D. J., Zou, L., Zhang, R., SalviaTrujillo, L., Kumosani, T., Xiao, H. (2015). Enhancing Nutraceutical Performance Using Excipient Foods: Designing Food Structures and Compositions to Increase Bioavailability,Comprehensive Reviews in Food Science and Food Safety Vol.14. https://doi.org/10.1111/1541-4337.12170

[18]. Bhowmik, D., Gopinath, H., Kumar, B. P., Duraivel, S., Kumar, K. P. S. (2013). Nutraceutical -A Bright Scope and Opportunity of Indian Healthcare Market, The pharma innovation, Vol. 1 No. 11, ISSN: 2277- 7695.

[19]. Herath, D., Cranfield, J., Henson, S. (2008). Who consumes functional foods and nutraceuticals in Canada? Results of cluster analysis of the 2006 
survey of Canadians' Demand for Food Products Supporting Health and Wellness, Appetite 51 , 256-265.

https://doi.org/10.1016/j.appet.2008.02.018

[20]. Dharti S., Gandhi, S., Shah, M. (2010). Nutraceuticals-portmanteau of science and nature , International Journal of Pharmaceutical Sciences Review and Research, Volume 5, Issue 3.

[21]. Daliri, E. B., Lee, B. H. (2015). Current Trends and Future Perspectives on Functional Foods and Nutraceuticals , Beneficial Microorganisms in Food and

Nutraceuticals,MicrobiologyMonographs27 https://doi.org/10.1007/978-3-319-23177-8_10

[22]. Nasri, H., Baradaran, A., Shirzad, H., Kopaei, M. R. (2014). New Concepts in Nutraceuticals as Alternative for Pharmaceuticals, International journal of preventive medicine, 1487-1499.

[23]. Alfawaz, H., Khan, N., Alfaifi, A., Shahrani, F. M., Tameem, H. M., Otaibi, S. F., Abudigin, W. I., AlShayaa, M. S., Al-Ghanim, S. A, Al-Daghri, N.M. (2017). Prevalence of dietary supplement use and associated factors among female college students in Saudi Arabia BMCWomen'sHealth,17:116.https://doi.org/10.11 86/s12905-017-0475-y

[24]. Singh, J., Sinha, S. (2012). Classification, regulatory acts and applications of nutraceuticals for health , International Journal of Pharmacy and Biological Sciences, Volume 2, Issue $1,177-187$.

[25]. Finley, J. W. (2016). The nutraceutical revolution: Emerging vision or broken dream? Understanding scientific and regulatory concerns, Clinical Research and RegulatoryAffairs,33:1,1-3. https://doi.org/10.3109/10601333.2016.1117096

[26]. Kumari, M., Jain, S., Singh, J. (2015). Nutraceutical - medicine of future , Journal of Global Biosciences ISSN 2320-1355 Volume 4, Number 7, pp. 2790-2794.

[27]. Vella, M. N., Stratton, L. M., Sheeshka, J., Duncan, A. M. (2014). Functional food awareness and perceptions in relation to information sources in older adults , Nutrition Journal. https://doi.org/10.1186/1475-2891-13-44
[28]. Helal, N. A., Eassa, H. A., Amer, A. M., Eltokhy, M. A., Edafiogho, I., Nounou, M. L. (2019). Nutraceuticals' Novel Formulations: The Good, the Bad, the Unknown and Patents Involved, Recent Patents on Drug Delivery \&Formulation,13.105-156.

https://doi.org/10.2174/1872211313666190503112 040

[29]. Chauhan, N. S., Alam, S., Mittal, A., Sahoo, J. (2017). Survey on awareness and extent of usage in local region of Uttar Pradesh ,India, Journal of Pharmaceutical and Pharmacological sciences. https://doi.org/10.29011/2574-7711.100029

[30]. Nwosu, O. K., Ubaoji, K. I. (2020). Nutraceuticals: History, Classification and Market Demand, Functional Foods and Nutraceuticals. https://doi.org/10.1007/978-3-030-42319-3_2

[31]. Pushpangadan, P., George, V., Sreedevi, P., Bincy, A. J., Anzar, S., Aswany, T., Ninawe, A. S., Ijinu, T. P. (2014). Functional foods and nutraceuticals with special focus on mother and child care, Annals of Phytomedicine 3(1): 4-24.

[32]. Patil, C.S. (2011). Current trends and future prospective of nutraceuticals in health promotion, BIOINFO Pharmaceutical Biotechnology , Volume 1, Issue 1, pp-01-07.

[33]. Costa, P. (2017). A current look at Nutraceuticals - key concepts and future prospects, Trends in Food Science \& Technology. https://doi.org/10.1016/j.tifs.2017.02.010

[34]. Jeyasekaran, P. (2015). Awareness on functional foods and nutraceuticals among educated home makers through booklet distribution, Journal of Medical Nutrition and Nutraceuticals,Vol4,Issue1. https://doi.org/10.4103/2278-019x.146160

[35]. Keservani, R. K., Sharma, A. K., Ahmad, F., Baig, M. E. (2014). Nutraceutical and Functional Food Regulations in India, Nutraceutical and Functional Food Regulations in the United States and Around the World. https://doi.org/10.1016/b978-0-12-4058705.00019-0

[36]. Sharma, R., Rawat , D. S. (2017). Indian Nutraceuticals Industry Current Scenario \& 
Future Trends, The Associated Chambers of Commerce and Industry of India , ASSOCHAM .

[37]. Teoh, S. L., Ngorsuraches, S., Lai, N. M., Bangpan, M., Chaiyakunapruk, N. (2018). Factors affecting consumers' decisions on the use of nutraceuticals , International Journal of Food Sciences and Nutrition.

https://doi.org/10.1080/09637486.2018.1538326

[38]. Zaman, T. U., Adetunji, H. A., Salih, E. F. M. (2017). nutraceuticals: a slow transition from preventive to curative healthcare and the perceptions among physicians and patients - a study of south Delhi in India, International Journal of Pharmaceutical Sciences and Research, 10.13040/IJPSR.0975-8232.8(7).3113-17.

[39]. Varzakas, T., Zakynthinos, G., Verpoort. F. (2016). Plant Food Residues as a Source of Nutraceuticals and Functional Foods. https://doi.org/10.3390/foods5040088

[40]. Chiba, T., Kobayashi, E., Okura, T., Sekimoto, M., Mizuno, H., Saito, M., Umegaki, K. (2020). An educational intervention improved knowledge of dietary supplements in college students , BMC Public Health. https://doi.org/10.1186/s12889020-08786-3

[41]. Golla, U. (2018). Emergence of nutraceuticals as the alternative medications for pharmaceuticals, International

JournalofComplementary\&AlternativeMedicine, $\mathrm{V}$ olume1,Issue3.

https://doi.org/10.15406/ijcam.2018.11.00388

[42]. Rishi, A. (2020). Nutraceuticals in India: A game changing opportunity in the healthcare and food industry, health. economictimes.indiatimes.com

[43]. Dr.Smarta, R.B. (2021). India market entry: Challenges and opportunities, vitalfoodinsights.com.

[44]. Grand View Research, (2020). Nutraceutical Market Size, Share \& Trends Analysis Report By Product (Dietary Supplements, Functional Foods, Functional Beverages), By Region, And Segment Forecasts, 2020 2027, www.grandviewresearch.com.
[45]. Mordor Intelligence, (2020). Nutraceuticals Market - Growth, Trends,Covid19Impact,AndForecasts(2021-2026), www.mordorintelligence.com.

[46]. Yadav, R., Mehta, R. (2020). The growing nutraceuticals market in India, investindia.gov.in.

\section{Cite this article as :}

Anushka Menon, Mugdhali Sawant, Shivangi Mishra, Prachi Bhatia, Sejal Rathod, "Awareness, Perception and Usage of Nutraceuticals in Indian Society", International Journal of Scientific Research in Science and Technology (IJSRST), Online ISSN : 2395-602X, Print ISSN : 2395-6011, Volume 8 Issue 5, pp. 399-414, September-October 2021. Available at doi : https://doi.org/10.32628/IJSRST218559 Journal URL : https://ijsrst.com/IJSRST218559 